ARTICLE

Received 8 Sep 2014 | Accepted 3 Oct 2014 | Published 21 Nov $2014 \quad$ DOl: 10.1038/ncomms6500

\title{
Asymmetric trapping of zwitterionic intermediates by sulphur ylides in a palladium-catalysed decarboxylation-cycloaddition sequence
}

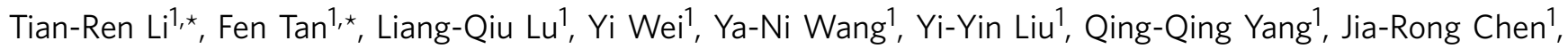
De-Qing Shi ${ }^{1} \&$ Wen-Jing Xiao ${ }^{1,2}$

Through nearly 50 years of development, sulphur ylides have been established as versatile and powerful reagents for the construction of carbocycles and heterocycles. Despite advances, two important and yet elusive bottlenecks continue to inhibit the advancement of this chemistry: a limited number of reagents with polar groups to react with sulphur ylides, and the wide utilization of chiral auxiliaries or substrates to achieve asymmetric cycloaddition processes in the majority of known reports. Herein, we apply an asymmetric palladium catalysis strategy to the chemistry of sulphur ylides to address these two fundamental problems. We thus achieve an unprecedented decarboxylation-cycloaddition sequence of cyclic allylic esters with sulphur ylides through the enantioselective trapping of Pd-stabilized zwitterionic intermediates by the ylides. As a result, a series of biologically and synthetically important 3-vinyl indolines are rapidly assembled with a high reaction efficiency and stereoselectivity.

\footnotetext{
${ }^{1}$ CCNU-uOttawa Joint Research Centre, Key Laboratory of Pesticide and Chemical Biology, Ministry of Education, College of Chemistry, Central China Normal University, 152 Luoyu Road, Wuhan, Hubei 430079, China. ${ }^{2}$ Collaborative Innovation Center of Chemical Science and Engineering (Tianjin), Tianjin 300072, China. * These authors contributed equally to this work. Correspondence and requests for materials should be addressed to L.-Q.L. (email: luliangqiu@mail.ccnu.edu.cn) or to W.-J.X. (email: wxiao@mail.ccnu.edu.cn).
} 
A sulphur ylide is a neutral dipolar molecule containing a carbanion and an adjacent sulphonium cation ${ }^{1}$. Because of their unique nucleophilic and then electrophilic reactivity, sulphur ylides are usually used as a versatile methylene synthon not only in synthetic laboratories ${ }^{2}$ but also in many bacteria ${ }^{3-5}$. For example, in the well-known JohnsonCorey-Chaykovsky reaction ${ }^{6}$, which was first discovered in the 1960s (refs 7,8), sulphur ylides can react with polar substrates (for example, aldehydes, ketones, imines and electron-deficient alkenes) to produce a wide range of significant small-ring molecules such as epoxides, aziridines and cyclopropanes. More importantly, their synthetic potential has been well demonstrated in the synthesis of numerous bioactive natural products and pharmaceuticals ${ }^{6,9,10}$. In the past decade, the cycloaddition chemistry of sulphur ylides has evolved dramatically beyond three-membered rings, largely as a consequence of the valuable contributions made by Aggarwal and co-workers ${ }^{11-22}$, among others. For instance, in 2006, Aggarwal's group developed an elegant epoxy-annulation sequence reaction of vinyl sulphonium salts, which are important precursor of sulphur ylides, to rapidly convert aminoaldehydes, ketones and imines into epoxide-fused heterocycles (Fig. la $)^{13}$. Significantly, a nine-step synthesis of (-)-balanol, an important protein kinase $\mathrm{C}$ inhibitor, was achieved starting from a chiral tert-butyl sulphinimine, with this methodology as a key step. Another impressive example was published by Tang's laboratory, who, in 2008, reported a highly efficient synthesis of cyclohexadiene epoxides via a tandem ylide Michael addition/epoxidation reaction of $\alpha, \beta$-unsaturated ketones with crotonate-derived sulphonium salts (Fig. 1b) ${ }^{14}$. They achieved high enantioselectivities and diastereoselectivities by employing camphor-derived chiral sulphonium salts. In the same year, our own group developed a cascade reaction involving acyl-stabilized sulphur ylides and nitroolefins-specifically, a $[4+1]$ cycloaddition/rearrangement cascade (Fig. 1c) ${ }^{15-16}$. Notably, chiral H-bonding catalysis was successfully applied to this transformation, affording enantio-enriched oxazolidin-2-one products in good efficiency and selectivity. Furthermore, the natural isolates valinoctin A and (-)-epi-cytoxazone with important biological activities were obtained through this cascade reaction. Despite impressive advances, the chemistry of sulphur ylides has still not achieved its full potential. Until very recently, $\pi$-Lewis-acid-gold complex-assisted cycloadditions of sulphur ylides with electron-neutral alkynes ${ }^{17,18}$ and alkenes ${ }^{19}$ have been sporadically reported. However, limited success has

a

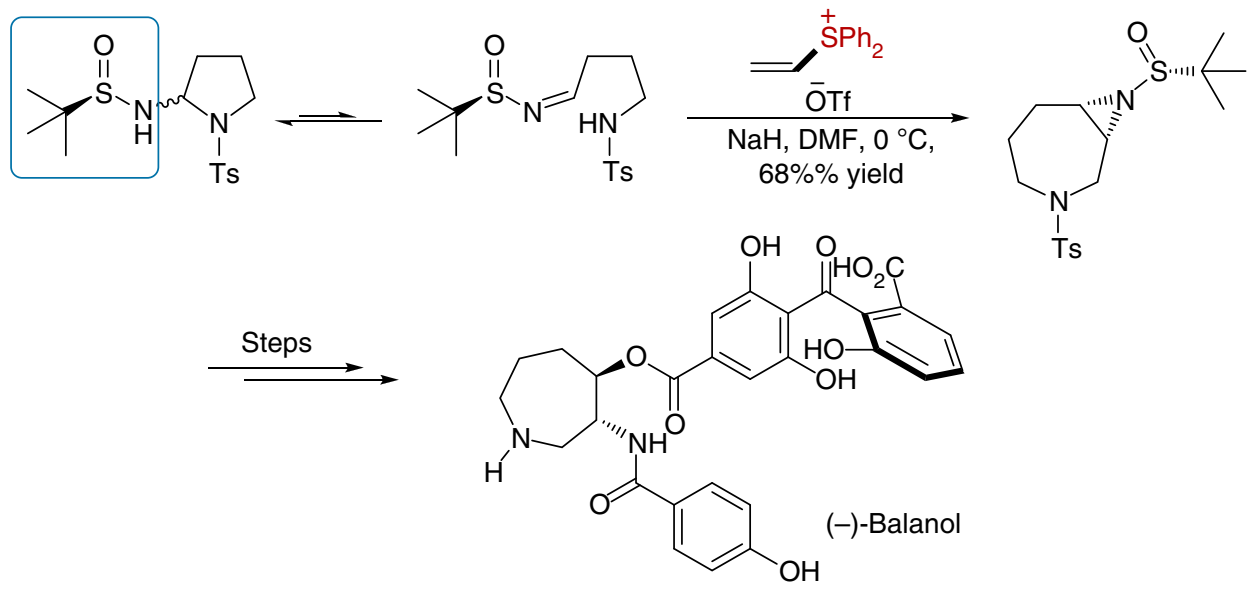

b

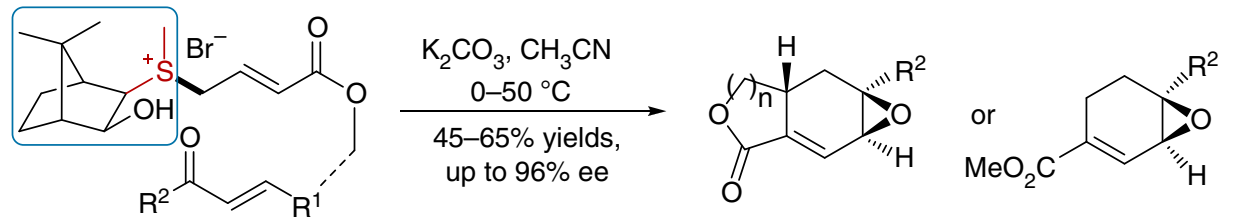

C<smiles>[R]C=C[N+](=O)[O-]</smiles><smiles>O=C1N[C@@H](P)[C@H](CO)O1</smiles>

$(-)$-epi-cytoxazone<smiles>CCCCCC[C@H](C(=O)O)[C@@H](N)[C@H](O)C(=O)N[C@H](C(=O)O)C(C)C</smiles>

Valinoctin A

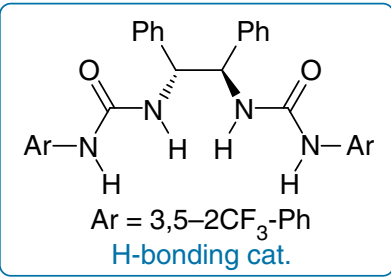

Figure 1 | Selected examples. (a) Aggarwal's work with vinyl sulphonium salts. (b) Tang's work with crotonate-derived sulphonium salts. (c) Our work with acyl-stabilized sulphur ylides. DMAP: N,N-dimethylpyridin-4-amine; 2-CTU: 1-(2-chlorophenyl)thiourea. 
been achieved using catalytic asymmetric technologies to achieve asymmetric cycloadditions of sulphur ylides ${ }^{16,20-22}$. In general, stoichiometric amounts of chiral auxiliaries or starting materials are required in the majority of reports to ensure good reaction efficiency and stereo-control. Therefore, the search for efficient asymmetric catalytic technologies and novel organic transformations of sulphur ylides, with the goal of increasing the diversity of the substrates and products, is still highly desirable.

Palladium-catalysed decarboxylation-cycloaddition (DC) reactions of cyclic allylic esters (Fig. 2a, A) have grown at a rapid pace in recent years ${ }^{23-26}$. The key to these successes is the in situ generation of the common Pd-stabilized zwitterionic intermediates B. From the perspective of reaction mechanisms, the nucleophilic part $\left(\mathbf{X}^{-}\right.$: nitrogen or $\alpha$-carbonyl anion) of these intermediates first reacts with electrophilic reagents such as electron-deficient alkenes, 1,3-dipoles and isocyanates and simultaneously affords new zwitterionic intermediates C. Subsequently, intramolecular allylations of the anion part $\left(\mathbf{N}^{-}\right)$by the electrophilic $\pi$-allylpalladium component deliver final cyclization products $\mathbf{D}$. Through this nucleophilic addition $(\mathrm{NuD})$ followed by electrophilic addition (ElD) process, a wide range of five-, six- and seven-membered ring compounds were efficiently constructed. In contrast, we wonder whether the apparent reversal of the ambident reactivity of these zwitterionic species could be used to further exploit novel cyclization reactions of cyclic allylic esters with nucleophilic reagents.

In the past several years, we are interested in carbo- and heterocycle synthesis by using acyl-stabilized sulphur ylides $^{12,15,16,27-29}$. We herein describe an unprecedented Pdcatalysed DC reactions of vinyl benzoxazinanones by using sulphur ylides to highly enantioselectively trap Pd-stabilized zwitterionic intermediates I (Fig. 2b). Notably, trapping of these intermediates with electrophilic components for cycloaddition was hitherto unknown and remains a challenging goal in this field of Pd-catalysed DC reactions because, as Tunge concluded, “...palladium-polarized aza-ortho-xylylenes (D) (note: intermediate I here) prefer to react with electron deficient olefins..."30. More significantly, via this approach, an important indoline core that is ubiquitous in many biologically active natural and synthetic chemicals could be conveniently constructed in a highly enantioselective and diastereoselective manner ${ }^{31-33}$. The method described here is a complement to previous efficient protocols including kinetic resolutions of racemic indolines 34 , catalytic asymmetric hydrogenation of indoles $^{35}$ and de nevo construction of chiral indolines via formal $[3+2]$ cycoloaddions of anilines and olefins ${ }^{36}$.

\section{Results}

Optimization of reaction conditions. The feasibility of this planned Pd-catalysed DC reaction was examined using vinyl benzoxazinanone 1a (1.0 equiv.) and sulphur ylide 2a (2.0 equiv.) in dichloromethane at room temperature. Notably, no reaction occurred in the absence of the Pd catalyst as shown in Fig. 3. The addition of a catalytic amount of $\left[\mathrm{Pd}\left(\mathrm{PPh}_{3}\right)_{4}\right](10 \mathrm{~mol} \%)$ promoted the synthesis of the desired indoline product in good isolated yield and with high selectivity (77\% yield, >95:5 diastereomer ratio (d.r.)). Encouraged by this initial result, we turned our attention to the development of Pd-catalysed asymmetric DC reactions. Initially, Trost's ligands (Table $1, \mathbf{L} \mathbf{1}$ and L2 $)^{37}$ together with $\mathrm{Pd}_{2}(\mathrm{dba})_{3} \bullet \mathrm{CHCl}_{3} \quad(5 \mathrm{~mol} \%$, dba: dibenzylideneacetone) were tested for the model reaction. These reaction conditions resulted in detectable enantioselectivities, moderate yields and complete diastereo-control (Table 1, entries 1 and 2: 55\% yield, >95:5 d.r., 20\% enantiomeric excess (e.e.) and $64 \%$ yield, $>95: 5$ d.r., $8 \%$ e.e.). A series of chiral ligands (L3-L8) were then evaluated for this asymmetric DC reaction. As summarized in Table 1, BINOL-derived chiral phosphoramidites (L4-L6, BINOL: 1,1'-binaphthalene-2,2'-diol) $)^{38}$ exhibited better enantiocontrol capacity (Table 1 , entries 4-6) than the others (Table 1, entries 1-2 and 7-8). The palladium complex with You's chiral ligand L6 (ref. 39) promoted this reaction with remarkably high efficiency and enantioselectivity (Table 1, entry 6: 99\% yield, $>95: 5$ d.r. and $83 \%$ e.e.). Other palladium sources were also screened, and $\mathrm{Pd}_{2}(\mathrm{dba})_{3}$ and $\mathrm{Pd}(\mathrm{acac})_{2}$ (acac: acetylacetonate) gave similar results in terms of both efficiency and selectivity. Afterwards, further efforts were made to improve the enantioselectivity. A significant solvent effect on enantioselectivity was observed, and chloroform was the solvent of choice (Table 1, entry 12: $99 \%$ yield, $>95: 5$ d.r., $89 \%$ e.e.). In addition, the enantiocontrol could be further improved when the reaction was conducted at $-40{ }^{\circ} \mathrm{C}$, although a prolonged reaction time was needed. The reaction efficiency and selectivity were retained when the amount of sulphur ylide was reduced to 1.5 equiv. (Table 1, entry 17: 95\% yield, >95:5 d.r., $94 \%$ e.e.).

a
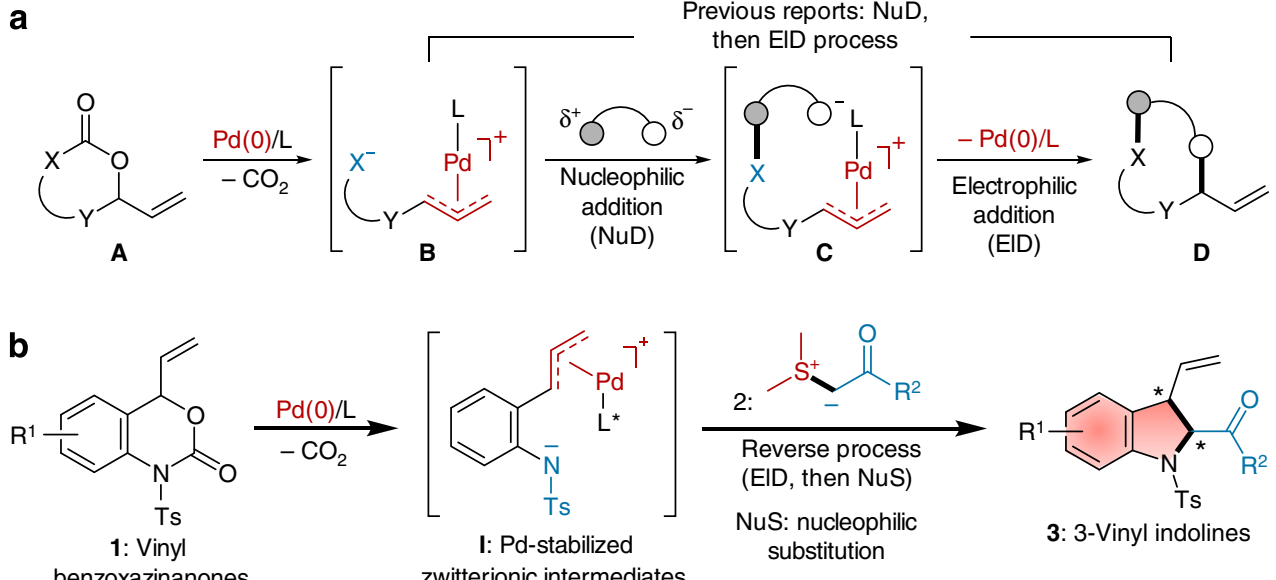

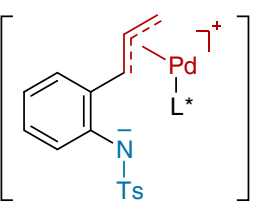

I: Pd-stabilized zwitterionic intermediates
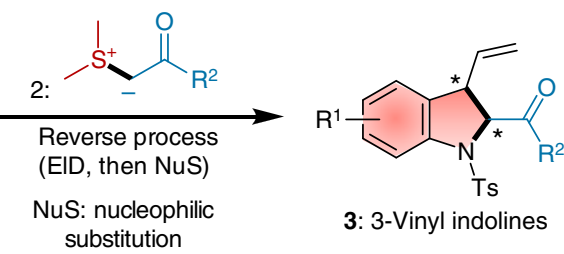

3: 3-Vinyl indolines

-Asymmetric palladium catalysis - Reverse reactivity - Prevalent indoline core

Figure 2 I Reaction design. (a) Previous reports: trapping of Pd-stabilized zwitterionic intermediates by electrophilic reagents for the decarboxylationcyclization sequence. (b) This work: trapping of Pd-stabilized aza-o-xylylenes by nucleophilic sulphur ylides. 
<smiles>[CH2][13CH2]N1C(=O)OC(C=C)c2ccccc21</smiles>

1a: $0.1 \mathrm{mmol}$

2a: $0.2 \mathrm{mmol}$

rac-3aa

(i) $\mathrm{Pd}\left(\mathrm{PPh}_{3}\right)_{4}\left(0 \mathrm{~mol} \%\right.$ ): no conversion; (ii) $\mathrm{Pd}\left(\mathrm{PPh}_{3}\right)_{4}(10 \mathrm{~mol} \%): 77 \%$ yield, $>95: 5$ d.r.

Figure 3 | Initial results. (i) No reaction occurred in the absence of the Pd catalyst. (ii) The desired product generated smoothly in the presence of $\mathrm{Pd}\left(\mathrm{PPh}_{3}\right)_{4}$.

Table 1 | Condition optimization of Pd-catalysed asymmetric DC reactions of vinyl benzoxazinanone 1a with sulphur ylide 2 a.<smiles>C=CC1OC(=O)N([18OH])c2ccccc21</smiles>

1a

$2 \mathbf{a}$

3aa

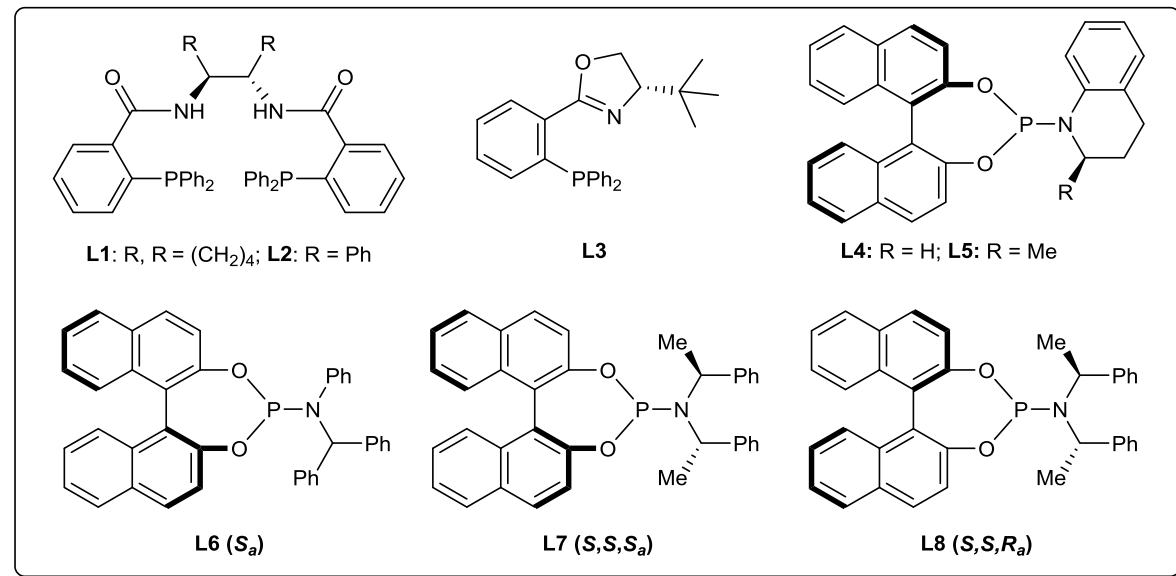

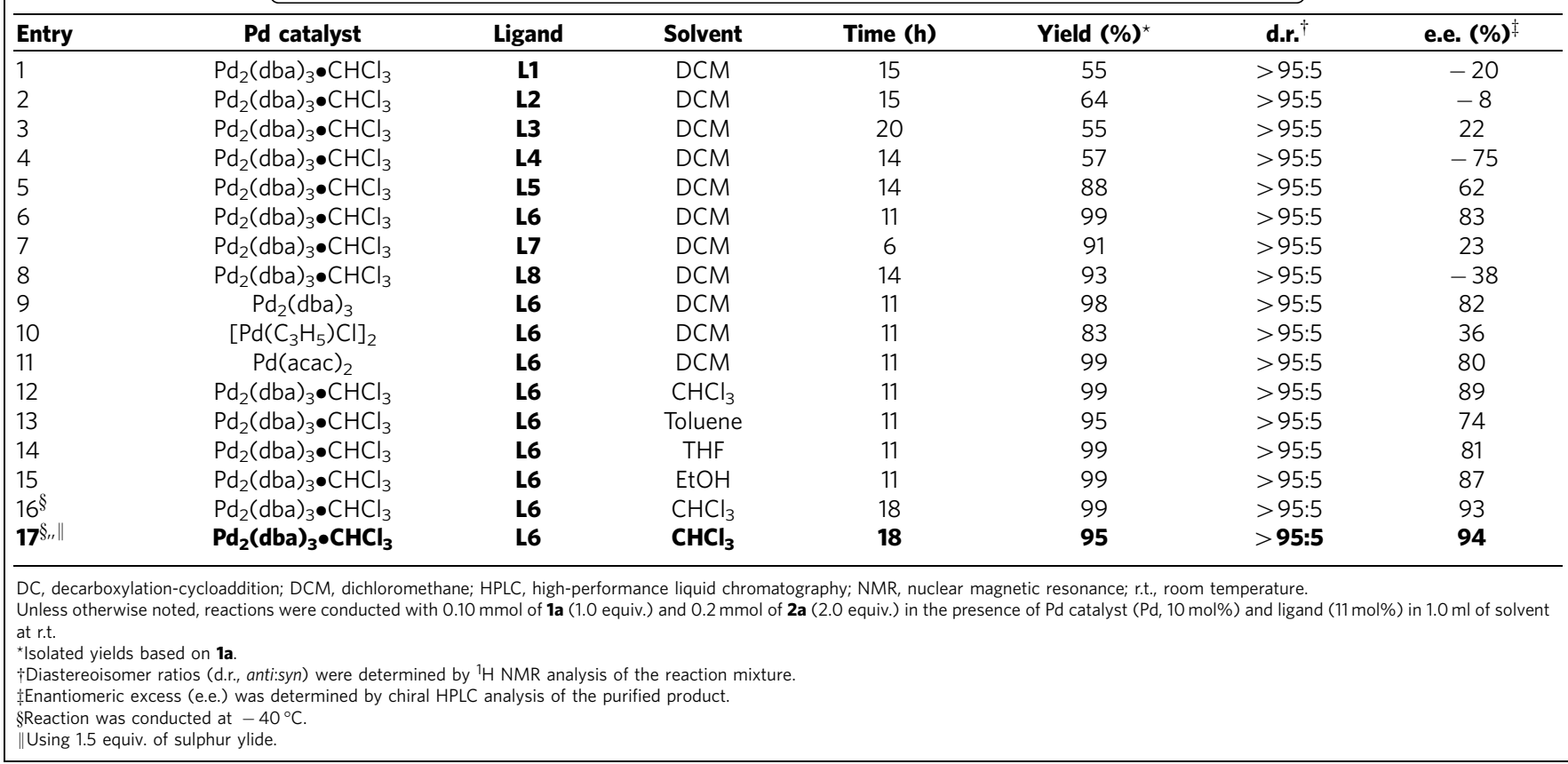


Table 2 | Survey of the vinyl benzoxazinanone and sulphur ylide scope in the Pd-catalysed asymmetric DC reactions.

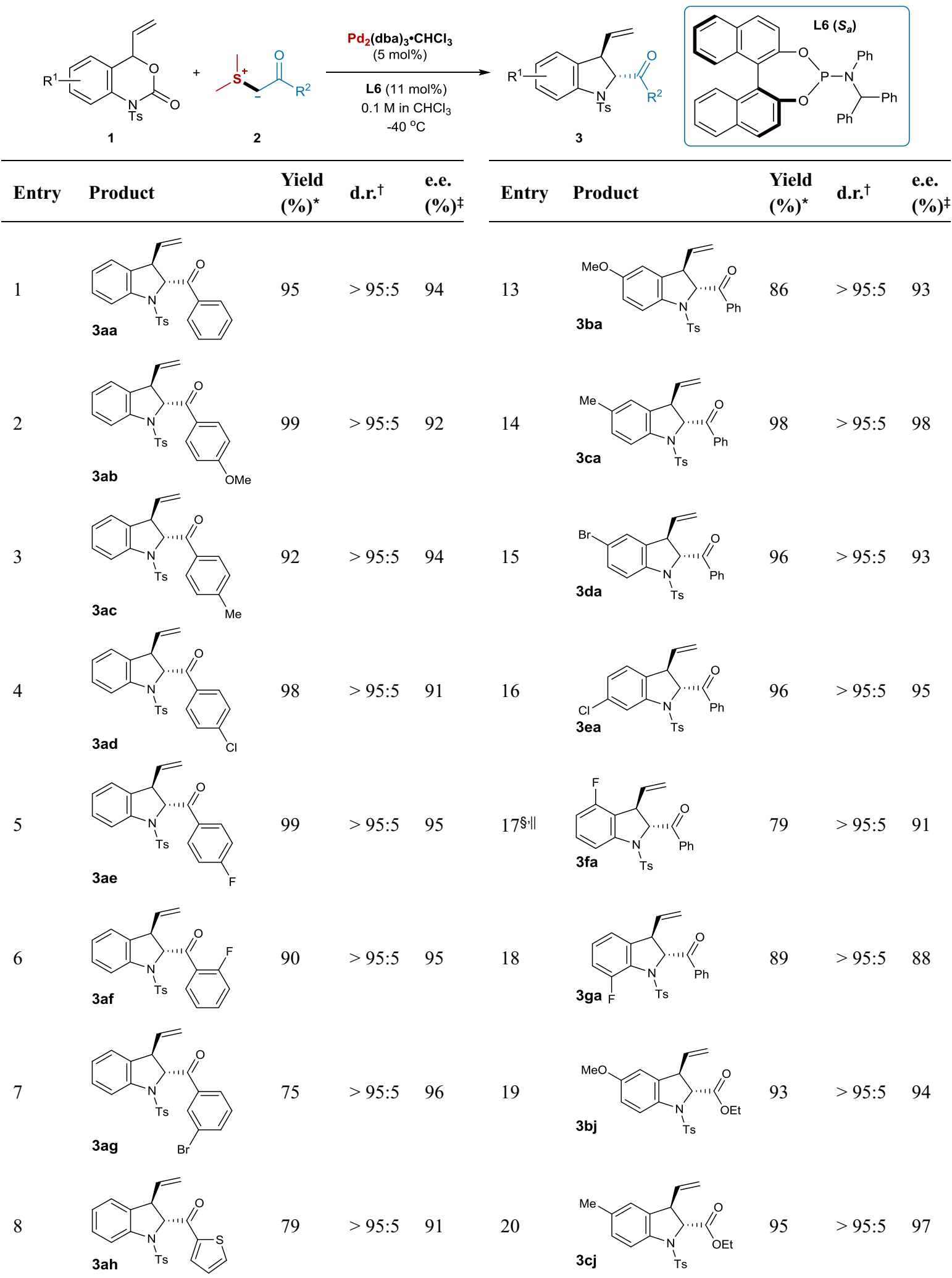

DC, decarboxylation-cycloaddition; HPLC, high-performance liquid chromatography; NMR, nuclear magnetic resonance.

Unless otherwise noted, reactions were conducted with $0.20 \mathrm{mmol}$ of $\mathbf{1}$ (1.0 equiv.) and $0.3 \mathrm{mmol}$ of $\mathbf{2}$ (1.5 equiv.) in the presence of $\mathrm{Pd}_{2}\left(\mathrm{dba}_{3} \cdot \mathrm{CHCl}_{3}(5 \mathrm{~mol} \%)\right.$ and $\mathbf{L 6}(12 \mathrm{~mol} \%)$ in $2.0 \mathrm{ml}$ of $\mathrm{CHCl} 3$ at $-40{ }^{\circ} \mathrm{C}$ *Isolated yields based on $\mathbf{1 a}$

Diastereoisomer ratios (d.r., antisyn) were determined by ${ }^{1} \mathrm{H}$ NMR analysis of the reaction mixture

tEnantiomeric excess (e.e.) was determined by chiral HPLC analysis of the purified product.

Seactions were conducted at $-20^{\circ} \mathrm{C}$ for entries $10-12,21,23-24$ and at $0^{\circ} \mathrm{C}$ for entry 17

Using 3.0 equiv. of sulphur ylide. 
Table 2 Continued.

\begin{tabular}{|c|c|c|c|c|c|c|c|c|c|}
\hline Entry & Product & $\begin{array}{l}\text { Yield } \\
(\%)^{\star}\end{array}$ & d.r. ${ }^{\dagger}$ & $\begin{array}{l}\text { e.e. } \\
(\%)^{\ddagger}\end{array}$ & Entry & Product & $\begin{array}{l}\text { Yield } \\
(\%)^{\star}\end{array}$ & d.r. ${ }^{\dagger}$ & $\begin{array}{l}\text { e.e. } \\
(\%)^{\ddagger}\end{array}$ \\
\hline 9 & 3ai & 86 & $>95: 5$ & 99 & $21 \S$ & 3dj & 81 & $>95: 5$ & 92 \\
\hline $10 \S$ & 3aj & 91 & $>95: 5$ & 93 & 22 & & 84 & $>95: 5$ & 89 \\
\hline $12^{\S} \|$ & 3al & 86 & $>95: 5$ & 95 & $24 \S$ & & 62 & $>95: 5$ & 83 \\
\hline
\end{tabular}

Substrate scope. With the optimum reaction conditions established, a variety of substrate combinations were evaluated to define the scope of Pd-catalysed asymmetric DC reactions. As highlighted in Table 2, a number of substituted benzoyl-stabilized sulphur ylides were determined to be suitable for this reaction. Variations of the electronic and steric properties of the substituents on the benzene ring had little effect on the reaction efficiency or stereoselectivity (Table 2, entries 1-6: $\geq 90 \%$ yield, $>95: 5$ d.r. and up to $96 \%$ e.e.); the exception was the meta-Brsubstituent (Table 2, entry 7: 75\% yield, $>95: 5$ d.r. and $96 \%$ e.e.), which resulted in a slightly lower yield. Heteroaryl-substituted acyl sulphur ylides (that is, 2-furanyl and 2-thiophenyl) were also useful reactants, providing the corresponding indoline products in high yields and with high stereoselectivities (Table 2, entries 8 and 9: $79 \%$ yield, $>95: 5$ d.r. and $91 \%$ e.e.; $86 \%$ yield, $>95: 5$ d.r. and $99 \%$ e.e.). Moreover, the scope of sulphur ylides can be significantly extended to alkoxyl-, alkenyl- and alkyl-acyl-substituted ones (Table 2, entries 10-12: 81-91\% yields, >95:5 d.r. and up to $93 \%$ e.e.).

From the perspective of product diversity, a wide range of vinyl benzoxazinanones were examined for the cycloaddition reaction of representative benzoyl- (2a) and ester-stabilized sulphur ylides (2j). As shown in Table 2, benzoxazinanone substrates with electron-rich and electron-deficient substitutes were compatible, being successfully converted into various indoline products with good results (Table 2, entries 13-15 and 19-21: 81-98\% yields, $>95: 5$ d.r. and up to $98 \%$ e.e.). Furthermore, this Pd-catalysed asymmetric DC reaction also tolerated variation of the position of the substituent on the benzene ring of vinyl benzoxazinanones, producing the corresponding indoline products in satisfactory isolated yields and stereoselectivities (Table 2, entries 16-18 and 22-24: $62-96 \%$ yields, $>95: 5$ d.r. and up to $95 \%$ e.e.). Notably, the incorporation of diverse halogen functional groups into the desired indoline products holds potential for further synthetic modifications through organometallic technologies ${ }^{40,41}$.

Synthetic versatility of reaction methodology. We then conducted a gram-scale reaction using the present chiral palladium catalysis system (Fig. 4a). No obvious erosive effect on reaction efficiency or selectivity ( $91 \%$ yield, $>95: 5$ d.r. and $93 \%$ e.e.) was observed. Moreover, the conventional synthetic operation can further enrich the diversity of the vinyl segment through the use of our previous cross-metathesis reaction conditions ${ }^{42}$. For example, chiral indoline 3aa was transformed to methyl and tert-butoxyl ester-substituted products (Fig. 4b,c) in good yields and with high optical purities in the presence of a catalytic amount of Ru metathesis catalyst and Lewis acid.

To further demonstrate the synthetic potential of this approach, the indoline product 3aa was subjected to other transformations (Fig. 4d-f). For example, reduction with sodium borohydride followed by propargylation gave 7 in high yield and selectivity ( $74 \%$ yield, $>95: 5$ d.r. and $93 \%$ e.e. for two steps). Then, a Pauson-Khand reaction with a cobalt catalyst under a $\mathrm{CO}$ atmosphere ${ }^{43}$ afforded the complex molecule 8 (45\% isolated yield, $93 \%$ e.e. and $>95: 5$ d.r.). This structure features a fused carbo-/heterocyclic architecture as well as a challenging sevenmembered ring. Moreover, after chiral indoline 3aa was reduced, a two-step operation including the deprotection of the tosyl group with magnesium powder and treatment with CDI provided the desired product 9 with an oxazolo[3,4-a]indol-3-one core $(77 \%$ isolated yield, $93 \%$ e.e. and $>95: 5$ d.r. in two steps). Significantly, this family of oxazolo[3,4-a]indol-3-ones exhibits significant synthetic value (Fig. $4 \mathrm{f})^{44-45}$, not only as a new class of potent antibacterial agents but also as important intermediates in the synthesis of natural indoline alkaloids. The optical purities of the compounds were not affected in these synthetic transformations, and new stereocentres were generated in good diastereoselectivities, which we established unambiguously using Nuclear Overhauser Enhancement Spectroscopy spectra.

\section{Discussion}

A possible mechanism for this Pd-catalysed asymmetric DC reaction is shown in Fig. 5a. Initially, Pd-polarized aza-o-xylylene I was obtained from substrate 1a through a decarboxylation reaction promoted by the chiral $\mathrm{Pd}^{0}$ catalyst (generated in situ from a $\mathrm{Pd}^{0}$ source and chiral phosphoramidite L6). Next, this 
a<smiles>C=CC1OC(=O)N([13CH3])c2ccccc21</smiles>

1a: $3.03 \mathrm{mmol}, 1.0 \mathrm{~g} \quad 2 \mathrm{a}: 4.55 \mathrm{mmol}, 0.82 \mathrm{~g}$<smiles>C=C[C@H]1c2ccccc2N(S)[C@H]1C(=O)c1ccccc1</smiles>

3aa: $1.11 \mathrm{~g}, 91 \%$ yield, $93 \%$ e.e., > 95:5 d.r.<smiles>O=S(=O)(c1ccccc1)N(c1ccccc1)C(c1ccccc1)P1Oc2ccc3ccccc3c2-c2c1ccc1ccccc21</smiles>

b<smiles>C=C[C@H]1c2ccccc2N([125I])[C@H]1C(=O)c1ccccc1</smiles>

3aa: $0.1 \mathrm{mmol}$, $93 \%$ e.e., $>95: 5$ d.r.<smiles>CC=C(C)C</smiles>

4a: $0.5 \mathrm{ml}$

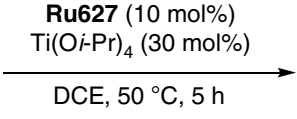

DCE, $50^{\circ} \mathrm{C}, 5 \mathrm{~h}$<smiles>C/C=C/[C@H]1c2ccccc2N(S)[C@@H]1C(=O)c1ccccc1</smiles>

5a: $94 \%$ yield, $93 \%$ e.e., $>95: 5$ d.r.

c<smiles>C=C[C@H]1c2ccccc2N([As])[C@H]1C(=O)c1ccccc1</smiles>

3aa: $0.1 \mathrm{mmol}$, $93 \%$ e.e., $>95: 5$ d.r.<smiles>C=CC(=O)OCC</smiles>

4b: $0.5 \mathrm{ml}$<smiles>CCCCOC(=O)/C=C/[C@H]1c2ccccc2N([As])[C@H]1C(=O)c1ccccc1</smiles>

5b: $88 \%$ yield, 93\% e.e., > 95:5 d.r.

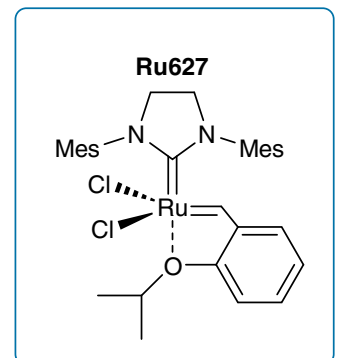

d<smiles>C=C[C@H]1c2ccccc2N(S)[C@H]1C(=O)C(C)C</smiles>
(i) $\mathrm{NaBH}_{4}, \mathrm{MeOH}$

3aa: $93 \%$ e.e., > (ii) $\mathrm{NaH}, \mathrm{THF}$ $\widehat{\mathrm{Br}}$ 95:5 d.r.

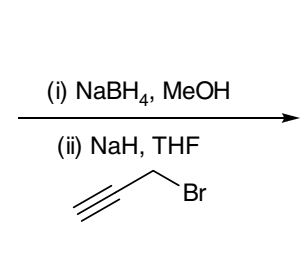<smiles>C#CCO[C@H](c1ccccc1)[C@H]1[C@H](C=C)c2ccccc2N1C</smiles>

(iii) $\mathrm{Co}_{2}(\mathrm{CO})_{8}$, TMTU

Toluene, $1 \mathrm{~atm}$ of $\mathrm{CO}$ $65^{\circ} \mathrm{C}$

7: $74 \%$ yield, 93\% e.e., > 95:5 d.r. (two steps)<smiles></smiles>

8:45\% yield, $93 \%$ e.e., $>95: 5$ d.r.

e<smiles>C=C[C@@H]1c2ccccc2N([13CH3])[C@H]1C(=O)c1ccccc1</smiles>
(i) $\mathrm{NaBH}_{4}, \mathrm{MeOH}$ 95:5 d.r.

6: $80 \%$ yield, $93 \%$ e.e., > 95:5 d.r.<smiles>C=CC1c2ccccc2N([As])[C@@H]1[C@H](O)c1ccccc1</smiles>
(v) CDI, DCM<smiles>C=C[C@H]1c2ccccc2N2C(=O)O[C@@H](c3ccccc3)[C@H]12</smiles>

9: $77 \%$ yield, 93\% e.e., > 95:5 d.r. (two steps)

f

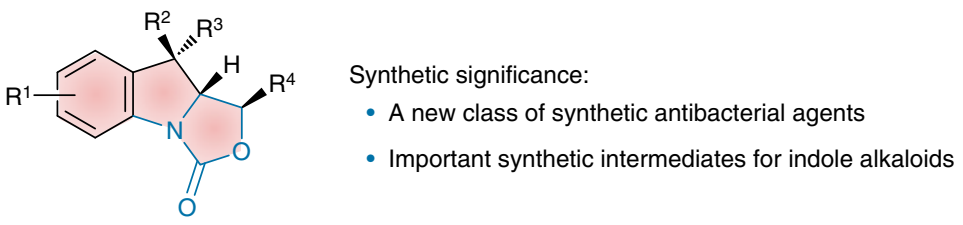

Figure 4 | Evaluating the potential of this strategy to address synthetically relevant problems. (a) Gram-scale reaction. (b,c) Application of the crossmetathesis (CM) reaction to introduce other substituents at the end of a terminal alkene. (d,e) Derivatization of chiral indoline product $\mathbf{3 a}$. (f) Synthetic significance of the oxazolo[3,4-a]indol-3-one core. Reagents and conditions: (i) $\mathrm{NaBH}_{4}$ (4 equiv.), $\mathrm{MeOH}, \mathrm{O}^{\circ} \mathrm{C}, 30$ min, then room temperature (r.t.), $2 \mathrm{~h}$; (ii) $\mathrm{NaH}$ (1.5 equiv.), propargyl bromide (1.3 equiv.), THF, r.t., $5 \mathrm{~h}$; (iii) $\mathrm{Co}_{2}(\mathrm{CO})_{8}\left(0.3\right.$ equiv.), $\mathrm{TMTU}$ (1.2 equiv.), $\mathrm{CO}(1 \mathrm{~atm})$, toluene, $65^{\circ} \mathrm{C}, 4 \mathrm{~h}$; (iv) $\mathrm{Mg}$ (powder, 10 equiv.), $\mathrm{MeOH}, \mathrm{N}_{2}, 12 \mathrm{~h}$; (V) CDI (1.1 equiv.), DCM, r.t., $12 \mathrm{~h}$. TMTU: tetramethyl thiourea; $\mathrm{CDI}$ : di(1H-imidazol-1-yl)methanone.

species reacted with sulphur ylide 1a to form Pd complex II through electronic interaction. A new $\mathrm{C}-\mathrm{C}$ bond was formed irreversibly via an intramolecular asymmetric allylation reaction, and the new intermediate III was generated in good regioselectivity and stereoselectivity. The subsequent decomposition of this species resulted in the regeneration of the chiral $\mathrm{Pd}^{0}$ catalyst and the simultaneous formation of the zwitterionic species IV. Finally, the desired chiral indoline product 3aa was achieved through bond rotation and $\mathrm{N}$-alkylation. The electrostatic interaction between the positive sulphonium ion and negative sulphamide anion was believed to play a pivotal role in the complete branched regioselectivity and good enantioselectivity (see the 
a

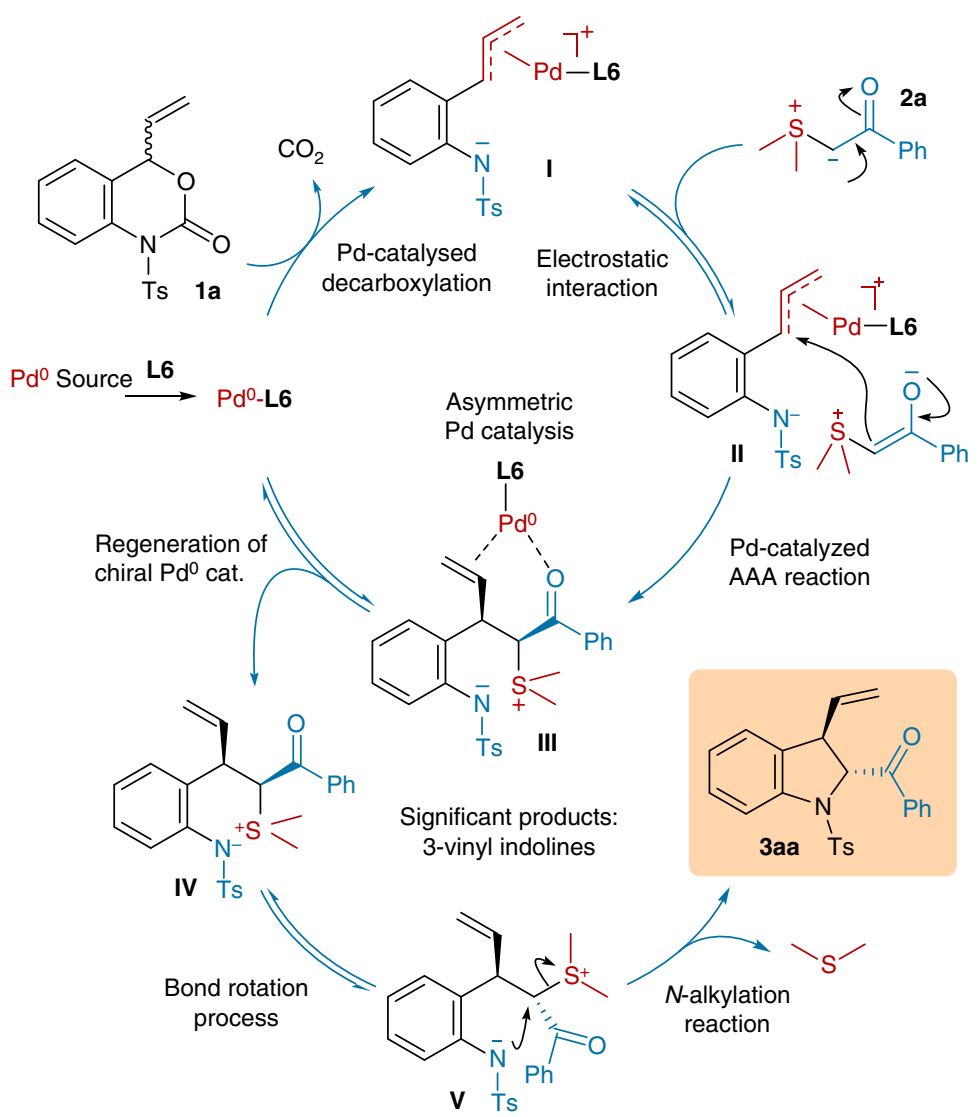

b

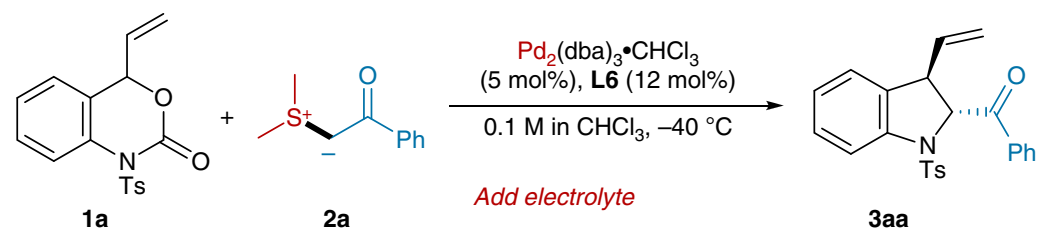

(i) $\left[\mathrm{NBu}_{4}\right]^{+} \mathrm{Br}^{-}$(1.0 equiv.): $43 \%$ yield, $>95: 5$ d.r. and $73 \%$ e.e.;

(ii) $\operatorname{LiBr}(1.0$ equiv.): no conversion; (ii) Lil (1.0 equiv.): $9 \%$ yield.

C
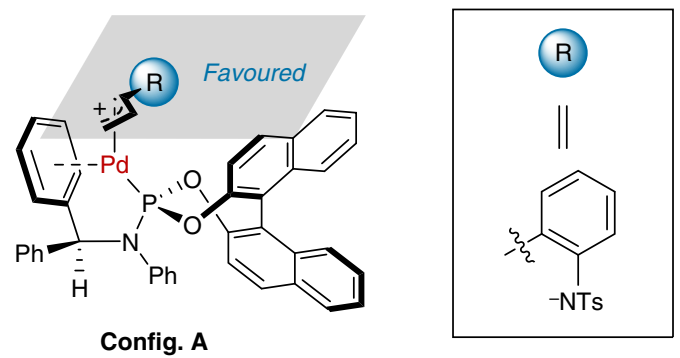

d

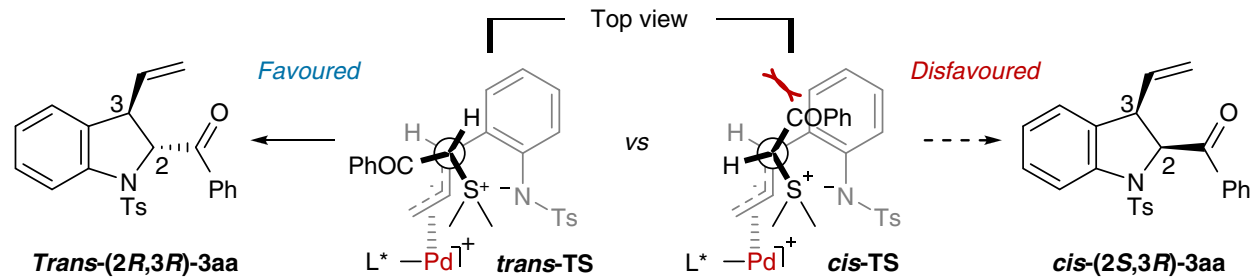

Figure 5 | Mechanism and stereochemistry analysis. (a) Our proposed reaction mechanism. (b) Electrolyte effects. (c) Proposed configurations of chiral Pd-polarized aza-o-xylylene (I). (d) Proposed transition states (Newman projection of the top view). 
stereochemistry analysis in Fig. $5 \mathrm{c}$,d). Although it has been demonstrated in previous work $^{46}$, this weak interaction was further confirmed by the control experiments. For example, when an electrolyte was introduced into the standard condition, the Pdcatalysed asymmetric DC reaction was completely inhibited $(\mathrm{LiBr})$ or its conversion and enantioselectivity were severely affected $\left(\mathrm{Bu}_{4} \mathrm{~N}^{+} \mathrm{Br}^{-}\right)$, perhaps because the electrostatic interaction in the key intermediate II (Fig. 5b) might be subjected to interference by the additional electrolyte.

The combination of Pd and BINOL-derived chiral phosphoramidites has been developed into a privileged catalyst in asymmetric organic transformations ${ }^{39}$ over the past 20 years. Significantly, many reactive Pd-allyl phosphoramidite complexes have been isolated, and their configurations have been established through X-ray diffraction (see Supplementary Fig. 40) and twodimensional (2D) NMR technologies ${ }^{47,48}$. On the basis of these advances, we proposed a favourable configuration (Fig. 5c, Config. A) for key intermediate I, as depicted in Fig. 5c; this configuration avoids the steric repulsion between the tosyl aniline component and the binaphthyl skeleton (Fig. 5c, Config. B). Because the bottom of this intermediate (Config. A) was blocked, the attack of the sulphur ylide 1a was assumed to be more favourable. It is well known that both dipole-dipole interactions and the steric hindrance of torsional rotations are critical to control the high E-selectivity and diastereoselectivity in the epoxide formation from sulphur ylides and the Wittig reaction of stabilized phosphonium ylides ${ }^{46,49}$. Accordingly, two Newman projections of possible transition states can be considered on the basis of electrostatic interactions (Fig. 5d, top view). In addition, we speculated that the indoline product trans- $(2 R, 3 R)-3$ aa and its epi-isomer cis-(2R,3R)-3aa could result from trans-TS and cisTS, respectively, followed by bond rotation and $\mathrm{N}$-alkylation processes. However, the former was believed to be more favourable than the latter because of its lower steric hindrance. This explanation of the stereochemistry is somewhat supported by the absolute configuration of cycloadduct 3aa, which was confirmed by XRD analysis. It is worthy to note that other possibilities for the high diastereoselectivity cannot be ruled out at the current stage. For example, reversible proton transfer of intermediate $\mathbf{I V / V}$ dynamically favours the diastereomer to undergo fast ring-closing step; the slow keto-enol tautomerism under basic condition thermodynamically favours transconfiguration product, which has been supported by the $\mathrm{D}_{2} \mathrm{O}$ experiment (see Supplementary Fig. 41).

In conclusion, we have achieved an enantioselective trapping of palladium-stabilized zwitterionic intermediates with nucleophilic dipole sulphur ylides for the first time. An unprecedented Pdcatalysed asymmetric decarboxylation-cyclization sequence of sulphur ylide with vinyl benzoxazinanones was achieved, providing a wide range of significant 3-vinyl indoline products in good reaction efficiencies (62-99\% yields) and stereoselectivities (up to $>95: 5$ d.r. and $99 \%$ e.e.). Notably, via the asymmetric palladium catalysis technology described here, the cycloaddition chemistry of the sulphur ylides was significantly extended to nonpolar reagents, specifically, cyclic allylic esters. Moreover, the corresponding asymmetric cycloaddition process also occurred in the presence of a catalytic amount of chiral ligand. Therefore, we believe this work will open new avenues for reaction design and carbocycle/heterocycle synthesis based on these versatile and powerful sulphur ylides.

\section{Methods}

Materials. Unless otherwise noted, materials were purchased from commercial suppliers and used without further purification. All the solvents were treated according to standard methods. Flash column chromatography was performed using 200-300 mesh silica gel. All air- and moisture-sensitive reactions were performed under an atmosphere of $\mathrm{N}_{2}$ in fire-dried glassware. The manipulations for Pd-catalysed reactions were carried out with standard Schlenk techniques under Ar. See Supplementary Methods for details.

General spectroscopic methods. ${ }^{1} \mathrm{H}$ NMR spectra were recorded on 400 or $600 \mathrm{MHz}$ spectrophotometers. ${ }^{13} \mathrm{C}$ NMR spectra were recorded on 100 or $150 \mathrm{MHz}$ with complete proton-decoupling spectrophotometers $\left(\mathrm{CDCl}_{3}: 77.0\right.$ p.p.m.). High resolution mass spectrometry (HRMS) was recorded on Agilent technologies 6224 time of flight (TOF) liquid chromatography-mass spectrometry (LC/MS) instrument or Bruker ultrafleXtreme matrix-assisted laser desorption/ionization-TOF (MALDI-TOF)/TOF mass spectrometer. e.e. values were determined by chiral HPLC with chiral columns (chiralpak AS-H column, chiralpak AD-H column, chiralpak OJ-H column, chiralpak IC-H column or chiralcel OD-H column) with hexane and $i-\mathrm{PrOH}$ as solvents. Optical rotations were measured with a polarimeter. ${ }^{1} \mathrm{H}$ NMR, ${ }^{13} \mathrm{C}$ NMR and HPLC spectra are supplied for all compounds: see Supplementary Figs 1-39 and Supplementary Table 1. See Supplementary Methods for the characterization data of all compounds related.

General procedure for $\mathrm{Pd}$-catalysed asymmetric $\mathrm{DC}$ reactions. In a flame-dried Schlenk tube under $\mathrm{N}_{2}, \mathrm{Pd}_{2}(\mathrm{dba})_{3} \bullet \mathrm{CHCl}_{3}(0.01 \mathrm{mmol}, 10.35 \mathrm{mg})$ and phosphoramidites ligand $\mathbf{L 6}(0.024 \mathrm{mmol}, 12.6 \mathrm{mg})$ were mixed in dry chloroform and stirred at room temperature for $20 \mathrm{~min}$. The mixture was then cooled to $-40^{\circ} \mathrm{C}$ and vinyl benzoxazinanone $\mathbf{1 a}(0.2 \mathrm{mmol}, 66 \mathrm{mg})$ and sulphur ylide $\mathbf{2 a}(0.3 \mathrm{mmol}$, $54 \mathrm{mg}$ ) were successively introduced. The resulting dark-green solution was stirred at this temperature until the reaction was completed (as indicated by thin-layer chromatography). After the solvent was evaporated under reduced pressure, the crude product was purified via flash chromatography $\left(\mathrm{SiO}_{2}, 12: 1\right.$ petroleum ether:ethyl acetate) to give chiral 3-vinyl indoline 3aa as a white solid. d.r. is $>95: 5$, as determined by ${ }^{1} \mathrm{H}$ NMR of the reaction mixture. e.e. is $94 \%$, as determined by HPLC (Daicel Chirapak AD, hexane/isopropanol $=70 / 30$, flow rate $1.0 \mathrm{ml} \mathrm{min}^{-1}$, $\left.\mathrm{T}=25^{\circ} \mathrm{C}, 254 \mathrm{~nm}\right): t_{\mathrm{R}}=13.175 \mathrm{~min}\left(\right.$ major), $t_{\mathrm{R}}=21.88 \min \left(\right.$ minor), $[\alpha]_{\mathrm{D}}^{25}=4.0$ $\left(\mathrm{c}=1.0, \mathrm{CHCl}_{3}\right)$.

\section{References}

1. Trost, B. M. \& Melvin, L. S. (eds) Sulfur Ylides (Academic Press, 1975).

2. McGarrigle, E. M. et al. Chalcogenides as organocatalyst. Chem. Rev. 107, 5841-5883 (2007).

3. Yan, F. \& Fujimori, D. G. RNA methylation by Radical SAM enzymes RlmN and Cfr proceeds via methylene transfer and hydride shift. Proc. Natl Acad. Sci. USA 108, 3930-3934 (2011).

4. Landgraf, B. J. \& Booker, S. J. The ylide has landed. Nature 498, 45-47 (2013)

5. Kim, J. et al. Structure-guided discovery of the metabolite carboxy-SAM that modulates tRNA function. Nature 498, 123-126 (2013).

6. Kürti, L. \& Czakó, B. Strategic Applications of Named Reactions in Organic Synthesis (Elsevier Academic Press, 2005).

7. Johnson, A. W. \& LaCount, R. B. The chemistry of ylids. VI. Dimethylsulfonium fluorenylide-a synthesis of epoxides. J. Am. Chem. Soc. 83, 417-423 (1961).

8. Corey, E. J. \& Chaykovsky, M. Dimethyloxosulfonium methylide $\left(\left(\mathrm{CH}_{3}\right)_{2} \mathrm{SOCH}_{2}\right)$ and dimethylsulfonium methylide $\left(\left(\mathrm{CH}_{3}\right)_{2} \mathrm{SCH}_{2}\right)$. Formation and application to organic synthesis. J. Am. Chem. Soc. 87, 1353-1364 (1965).

9. Nicolaou, K. C., Sun, Y.-P., Guduru, R., Banerji, B. \& Chen, D. Y.-K. Total synthesis of the originally proposed and revised structures of palmerolide A and isomers thereof. J. Am. Chem. Soc. 130, 3633-3644 (2008).

10. Sarabia, F., Martín-Gálvez, F., Chammaa, S., Martín-Ortiz, L. \& Sánchez-Ruiz, A. Chiral sulfur ylides for the synthesis of bengamide E and analogues. J. Org. Chem. 75, 5526-5532 (2010).

11. Sun, X.-L. \& Tang, Y. Ylide-initiated Michael addition-cyclization reactions beyond cyclopropanes. Acc. Chem. Res. 41, 937-948 (2008).

12. Lu, L.-Q., Chen, J.-R. \& Xiao, W.-J. Development of cascade reactions for the concise construction of diverse heterocyclic architectures. Acc. Chem. Res. 45, 1278-1293 (2012).

13. Unthank, M. G., Hussain, N. \& Aggarwal, V. K. The Use of vinyl sulfonium salts in the stereo-controlled asymmetric synthesis of epoxide- and aziridinefused heterocycles: application to the synthesis of (-)-balanol. Angew. Chem. Int. Ed. 45, 7066-7069 (2006).

14. Wang, Q.-G. et al. Tandem Michael addition/ylide epoxidation for the synthesis of highly functionalized cyclohexadiene epoxide derivatives. J. Am. Chem. Soc. 130, 5408-5409 (2008).

15. Lu, L.-Q. et al. A new entry to cascade organocatalysis: reactions of stable sulfur ylides and nitroolefins sequentially catalyzed by thiourea and DMAP. J. Am. Chem. Soc. 130, 6946-6948 (2008).

16. Lu, L.-Q. et al. Hydrogen-bond-mediated asymmetric cascade reaction of stable sulfur ylides with nitroolefins: scope, application and mechanism. Chem. Eur. J. 18, 4073-4079 (2012).

17. Kramer, S. \& Skrydstrup, T. Gold-catalyzed carbene transfer to alkynes: access to 2,4-disubstituted furans. Angew. Chem. Int. Ed. 51, 468-4684 (2012). 
18. Huang, X. et al. Gold-catalyzed synthesis of furans and furanones from sulfur ylides. Angew. Chem. Int. Ed. 51, 8886-8890 (2012).

19. Huang, X., Klimczyk, S., Veiros, L. F. \& Maulide, N. Stereoselective intramolecular cyclopropanation through catalytic olefin activation. Chem. Sci. 4, 1105-1110 (2013).

20. Aggarwal, V. K., Charmant, J., Dudin, L., Porcelloni, M. \& Richardson, J. Effect of sulfide structure on enantioselectivity in catalytic asymmetric epoxidation of aldehydes; mechanistic insights and implications. Proc. Natl Acad. Sci. USA 101, 5467-5471 (2004).

21. Kunz, R. K. \& MacMillan, D. W. C. Enantioselective organocatalytic cyclopropanations. The identification of a new class of iminium catalyst based upon directed electrostatic activations. J. Am. Chem. Soc. 127, 3240-3241 (2005).

22. Chen, J.-R. et al. Enantioselective synthesis of dihydropyrazoles by formal $[4+1]$ cycloaddition of in situ-derived azoalkenes and sulfur ylides. J. Am Chem. Soc. 134, 6924-6927 (2012).

23. Weaver, J. D., Recio, A., Grenning, A. J. \& Tunge, J. A. Transition metalcatalyzed decarboxylative allylation and benzylation reactions. Chem. Rev. 111, 1846-1913 (2011).

24. Shintani, R., Murakami, M. \& Hayashi, T. $\gamma$-Methylidene- $\alpha$-valerolactones as a coupling partner for cycloaddition: palladium-catalyzed [4+3] cycloaddition with nitrones. J. Am. Chem. Soc. 129, 12356-12357 (2007).

25. Wang, C. \& Tunge, J. A. Asymmetric cycloadditions of palladium-polarized aza-o-xylylenes. J. Am. Chem. Soc. 130, 8118-8119 (2008)

26. Ohmatsu, K., Imagawa, N. \& Ooi, T. Ligand-enabled multiple absolute stereocontrol in metal-catalysed cycloaddition for construction of contiguous all-carbon quaternary stereocentres. Nat. Chem. 6, 47-51 (2014).

27. Lu, L.-Q. et al. Construction of fused heterocyclic architectures by formal $[4+1] /[3+2]$ cycloaddition cascade of sulfur ylides and nitroolefins. Angew. Chem. Int. Ed. 48, 9542-9545 (2009).

28. Lu, L.-Q. et al. Tuning electronic and steric effects: highly enantioselective $[4+1]$ pyrroline annulation of sulfur ylides with $\alpha, \beta$-unsaturated imines. Angew. Chem. Int. Ed. 49, 4495-4498 (2010).

29. Yang, Q.-Q. et al. Synthesis of indoles through highly efficient cascade reactions of sulfur ylides and $\mathrm{N}$-(ortho-chloromethyl)aryl amides. Angew. Chem. Int. Ed. 51, 9137-9140 (2012).

30. Wang, C., Pahadi, N. \& Tunge, J. A. Decarboxylative cyclizations and cycloadditions of palladium-polarized aza-ortho-xylylenes. Tetrahedron $\mathbf{6 5}$, 5102-5109 (2009).

31. Kariba, R. M., Houghton, P. J. \& Yenesew, A. Antimicrobial activities of a new schizozygane indoline alkaloid from schizozygia coffaeoides and the revised structure of isoschizogaline. J. Nat. Prod. 65, 566-569 (2002).

32. Zhang, D., Song, H. \& Qin, Y. Total synthesis of indoline alkaloids: a cyclopropanation strategy. Acc. Chem. Res. 44, 447-457 (2011).

33. Jones, S. B., Simmons, B., Mastracchio, A. \& MacMillan, D. W. C. Collective synthesis of natural products by means of organocascade catalysis. Nature 475, 183-188 (2011)

34. Arp, F. O. \& Fu, G. C. Kinetic resolutions of indolines by a nonenzymatic acylation catalyst. J. Am. Chem. Soc. 128, 14264-14265 (2006)

35. Wang, D.-S. et al. Pd-catalyzed asymmetric hydrogenation of unprotected indoles activated by brønsted acids. J. Am. Chem. Soc. 132, 8909-8911 (2010)

36. Hyde, A. M. \& Buchwald, S. L. Palladium-catalyzed $\gamma$-arylation of $\beta, \gamma$ unsaturated ketones: application to a one-pot synthesis of tricyclic indolines. Angew. Chem. Int. Ed. 47, 177-180 (2008)

37. Trost, B. M., Van Vranken, D. L. \& Bingel, C. A modular approach for ligand design for asymmetric allylic alkylations via enantioselective palladium-catalyzed ionizations. J. Am. Chem. Soc. 114, 9327-9343 (1992).

38. Teichert, J. F. \& Feringa, B. L. Phosphoramidites: privileged ligands in asymmetric catalysis. Angew. Chem. Int. Ed. 49, 2486-2528 (2010).

39. Liu, W.-B., Zheng, C., Zhuo, C.-X., Dai, L.-X. \& You, S.-L. Iridium-catalyzed allylic alkylation reaction with $\mathrm{N}$-aryl phosphoramidite ligands: scope and mechanistic studies. J. Am. Chem. Soc. 134, 4812-4821 (2012).
40. Beller, M. \& Bolm, C. Transition Metals for Organic Synthesis: Building Blocks and Fine Chemicals (Wiley-VCH, 2004).

41. Diederich, F. \& Stang, J. P. Metal-Catalyzed Cross-Coupling Reactions (Wiley-VCH, 2004).

42. Yang, Q., Xiao, W.-J. \& Yu, Z.-K. Lewis acid assisted ring-closing metathesis of chiral diallylamines: an efficient approach to enantiopure pyrrolidine derivatives. Org. Lett. 7, 871-874 (2005).

43. He, H., Liu, W.-B., Dai, L.-X. \& You, S.-L. Enantioselective synthesis of 2,3-dihydro-1h-benzo[b]azepines: iridium-catalyzed tandem allylic vinylation/ amination reaction. Angew. Chem. Int. Ed. 49, 1496-1499 (2010).

44. Gleave, D. M. \& Brickner, S. J. Oxazolidinone antibacterial agents. An enantioselective synthesis of the $[6,5,5]$ tricyclic fused oxazolidinone ring system and application to the synthesis of a rigid DuP 721 analogue. J. Org. Chem. 61, 6470-6647 (1996).

45. Padwa, A. et al. A new strategy toward indole alkaloids involving an intramolecular cycloaddition/rearrangement cascade. J. Org. Chem. 69, 3735-3745 (2004).

46. Aggarwal, V. K., Harvey, J. N. \& Richardson, J. Unraveling the mechanism of epoxide formation from sulfur ylides and aldehydes. J. Am. Chem. Soc. 124, 5747-5756 (2002).

47. Filipuzzi, S. \& Pregosin, P. S. Palladium-allyl phosphoramidite complexes: solid-state structures and solution dynamics. Organometallics 25, 5955-5964 (2006).

48. Filipuzzi, S., Pregosin, P. S., Calhorda, J. M. \& Costa, P. J. Weak $\eta^{2}$-olefin bonding in palladium and platinum allyl cationic complexes containing chiral monodentate ligands with $\alpha$-phenyl methyl amine side chains. Organometallics 27, 2949-2958 (2008).

49. Robiette, R., Richardson, J., Aggarwal, V. K. \& Harvey, J. N. On the origin of high $E$ selectivity in the Wittig reaction of stabilized ylides: importance of dipole-dipole interactions. J. Am. Chem. Soc. 127, 13468-13469 (2005)

\section{Acknowledgements}

We thank the National Science Foundation of China (NO. 21232003, 21202053 and 21272087) and the National Basic Research Program of China (2011CB808603) for support of this research. We thank Dr Xiang-Gao Meng and Dr Fang Li who carried out the X-ray crystallographic analysis and NOE spectroscopy analysis, respectively.

\section{Author contributions}

T.-R.L. and F.T. are responsible for the plan and implementation of the experimental work. L.-Q.L. and W.-J.X. designed and guided this project and co-wrote the manuscript Y.W., Y.-N.W., Y.-Y.L., Q.-Q.Y., J.-R.C. and D.-Q.S. have successfully done experiments in this project. All authors discussed the results and commented on the manuscript.

\section{Additional information}

Accession codes: The X-ray crystallographic coordinates for structures reported in this Article have been deposited at the Cambridge Crystallographic Data Centre (CCDC), under deposition numbers CCDC 1009688. These data can be obtained free of charge from The Cambridge Crystallographic Data Centre via http://www.ccdc.cam.ac.uk/ data_request/cif

Supplementary Information accompanies this paper at http://www.nature.com/ naturecommunications

Competing financial interests: The authors declare no competing financial interests.

Reprints and permission information is available online at http://npg.nature.com/ reprintsandpermissions/

How to cite this article: Li, T.-R. et al. Asymmetric trapping of zwitterionic inter mediates by sulphur ylides in a palladium-catalysed decarboxylation-cycloaddition sequence. Nat. Commun. 5:5500 doi: 10.1038/ncomms6500 (2014). 